\title{
EVIDENCE FOR RADIOGENIC SULFUR-32 IN TYPE AB PRESOLAR SILICON CARBIDE GRAINS?
}

\author{
Wataru Fujiya ${ }^{1,2}$, Peter Hoppe ${ }^{1}$, Ernst Zinner ${ }^{3}$, Marco Pignatari ${ }^{4,6}$, and Falk Herwig ${ }^{5,6}$ \\ ${ }^{1}$ Max Planck Institute for Chemistry, Hahn-Meitner-Weg 1, D-55128 Mainz, Germany; wataru.fujiya@ mpic.de, peter.hoppe@ mpic.de \\ ${ }^{2}$ Department of Earth and Planetary Science, University of Tokyo, 7-3-1 Hongo, Bunkyo-ku, 113-0033 Tokyo, Japan \\ ${ }^{3}$ Laboratory for Space Sciences and Physics Department, Campus Box 1105, Washington University, St. Louis, MO 63130, USA; ekz@wustl.edu \\ ${ }^{4}$ Department of Physics, University of Basel, Klingelbergstrasse 82, CH-4056 Basel, Switzerland; mpignatari@ gmail.com \\ ${ }^{5}$ Department of Physics \& Astronomy, University of Victoria, Canada, P.O. Box 3055, Victoria, BC V8W 3P6, Canada; fherwig@ uvic.ca \\ Received 2013 July 9; accepted 2013 September 20; published 2013 October 4
}

\begin{abstract}
We report $\mathrm{C}, \mathrm{Si}$, and $\mathrm{S}$ isotope measurements on 34 presolar silicon carbide grains of Type $\mathrm{AB}$, characterized by ${ }^{12} \mathrm{C} /{ }^{13} \mathrm{C}<10$. Nitrogen, $\mathrm{Mg}-\mathrm{Al}-$, and $\mathrm{Ca}-\mathrm{Ti}$-isotopic compositions were measured on a subset of these grains. Three grains show large ${ }^{32} \mathrm{~S}$ excesses, a signature that has been previously observed for grains from supernovae ( $\mathrm{SNe}$ ). Enrichments in ${ }^{32} \mathrm{~S}$ may be due to contributions from the $\mathrm{Si} / \mathrm{S}$ zone and the result of $\mathrm{S}$ molecule chemistry in still unmixed SN ejecta or due to incorporation of radioactive ${ }^{32} \mathrm{Si}$ from C-rich explosive He shell ejecta. However, a $\mathrm{SN}$ origin remains unlikely for the three $\mathrm{AB}$ grains considered here, because of missing evidence for ${ }^{44} \mathrm{Ti}$, relatively low ${ }^{26} \mathrm{Al} /{ }^{27} \mathrm{Al}$ ratios (a few times $10^{-3}$ ), and radiogenic ${ }^{32} \mathrm{~S}$ along with low ${ }^{12} \mathrm{C} /{ }^{13} \mathrm{C}$ ratios. Instead, we show that born-again asymptotic giant branch (AGB) stars that have undergone a very-late thermal pulse (VLTP), known to have low ${ }^{12} \mathrm{C} /{ }^{13} \mathrm{C}$ ratios and enhanced abundances of the light $s$-process elements, can produce ${ }^{32} \mathrm{Si}$, which makes such stars attractive sources for $\mathrm{AB}$ grains with ${ }^{32} \mathrm{~S}$ excesses. This lends support to the proposal that at least some AB grains originate from born-again AGB stars, although uncertainties in the born-again AGB star models and possible variations of initial $\mathrm{S}$-isotopic compositions in the parent stars of $\mathrm{AB}$ grains make it difficult to draw a definitive conclusion.
\end{abstract}

Key words: astrochemistry - circumstellar matter - nuclear reactions, nucleosynthesis, abundances supernovae: general

Online-only material: color figures

\section{INTRODUCTION}

Small quantities of stardust are found in primitive meteorites, interplanetary dust particles, and cometary matter (Zinner 2007). These so-called presolar grains condensed in the winds of low-mass asymptotic giant branch (AGB) stars and in the ejecta of stellar explosions. Presolar grains carry huge isotopic anomalies for various elements, which reflect nucleosynthetic and mixing processes in their parent stars. They survived the passage through the interstellar medium (ISM) and solar system formation largely intact, making them unique samples of stellar material that can be analyzed in detail in the laboratory.

Silicon carbide $(\mathrm{SiC})$ is the best-studied presolar mineral. The majority of presolar $\mathrm{SiC}$ grains ( $\sim 90 \%)$ belong to the so-called mainstream (MS) category, characterized by ${ }^{12} \mathrm{C} /{ }^{13} \mathrm{C}$ ratios of $10-100,{ }^{14} \mathrm{~N} /{ }^{15} \mathrm{~N}$ ratios with a wide distribution but, on average, higher than solar, and Si-isotopic compositions that in a Si-three isotope representation plot along a line with slope $\sim 1.3$ (the $\mathrm{Si}$ "MS line"; Zinner et al. 2006). The isotopic compositions of C and $\mathrm{Si}$ and, more importantly, of heavy trace elements contained in MS grains indicate that they originate from $1-3 M_{\odot}$ AGB stars of close-to-solar metallicity (Lugaro et al. 2003).

Silicon carbide grains from Type II supernovae ( $\mathrm{SNe}$ II), the $\mathrm{X}$ and $\mathrm{C}$ grains, are rare. Note that previously the $\mathrm{C}$ grains have also been named "unusual" or U/C grains. Here, we define $\mathrm{C}$ grains as having $\delta^{29,30} \mathrm{Si}>300 \% 0\left(\delta^{\mathrm{i}} \mathrm{Si}=\left[\left({ }^{\mathrm{i}} \mathrm{Si} /{ }^{28} \mathrm{Si}\right)_{\text {grain }} /\right.\right.$ $\left.\left[\left({ }^{\mathrm{i}} \mathrm{Si} /{ }^{28} \mathrm{Si}\right)_{\odot}-1\right] \times 1000\right)$ and ${ }^{12} \mathrm{C} /{ }^{13} \mathrm{C}>10$. The $\mathrm{X}$ grains have isotopically light $\mathrm{Si}$, i.e., large excesses in ${ }^{28} \mathrm{Si}\left(\delta^{29,30} \mathrm{Si}<\right.$ $-100 \%$ ), isotopically light or heavy $\mathrm{C}$, heavy $\mathrm{N}$, and high

\footnotetext{
${ }^{6}$ NuGrid collaboration, http://www.nugridstars.org
}

inferred ${ }^{26} \mathrm{Al} /{ }^{27} \mathrm{Al}$ ratios of $0.1-1$ (e.g., Hoppe et al. 2000; Lin et al. 2010). Observed ${ }^{44} \mathrm{Ca}$ excesses can be satisfactorily explained only by the decay of ${ }^{44} \mathrm{Ti}$, which is synthesized in significant amounts only in SNe II (Woosley et al. 1973; Timmes et al. 1996; Pignatari et al. 2013a), providing definitive proof of the SN II origin of X grains (Nittler et al. 1996; Hoppe et al. 1996). Except for isotopically heavy $\mathrm{Si}, \mathrm{C}$ grains exhibit the same isotopic signatures as X grains (Hoppe et al. 2012), including ${ }^{32} \mathrm{~S}$ excesses. In $\mathrm{X}$ grains, ${ }^{32} \mathrm{~S}$ could have originated either from the Si/S zone (e.g., Rauscher et al. 2002) or from the bottom of the $\mathrm{He} / \mathrm{C}$ zone experiencing explosive He burning at high shock velocities (Pignatari et al. 2013a). In C grains, ${ }^{32} \mathrm{~S}$ results instead from the decay of radioactive ${ }^{32} \mathrm{Si}$ (half-life 153 yr; Pignatari et al. 2013b).

$\mathrm{SiC}$ grains of Type $\mathrm{AB}$ have ${ }^{12} \mathrm{C} /{ }^{13} \mathrm{C}<10$ (Amari et al. 2001). They account for $\sim 4 \%$ of the presolar $\mathrm{SiC}$ population. $\mathrm{N}$-isotopic compositions are highly variable, with ${ }^{14} \mathrm{~N} /{ }^{15} \mathrm{~N}$ ratios ranging from 30 to 10,000 . While the $\mathrm{AB}$ grains have $\mathrm{Si}$-isotopic compositions similar to those of MS grains, they tend to have higher ${ }^{26} \mathrm{Al} /{ }^{27} \mathrm{Al}$ ratios of typically $10^{-3}$ to $10^{-2}$ (Amari et al. 2001). Unlike the origin of MS grains, that of $A B$ grains is still a matter of debate. The proposed stellar sources are J-type carbon stars (Lambert et al. 1986) and born-again AGB stars, such as Sakurai's object (Asplund et al. 1999). J-type carbon stars, which have low ${ }^{12} \mathrm{C} /{ }^{13} \mathrm{C}$ ratios, are viable candidate sources of $\mathrm{AB}$ grains without enrichments in $s$-process elements (Hedrosa et al. 2013). Unfortunately, the nature of J-type carbon stars is still not well understood; but a proposed scenario involves stellar mergers recently investigated by Zhang \& Jeffery (2012). Born-again AGB stars might be the source of $\mathrm{AB}$ grains with enhancements of $s$-process elements, in line with astronomical observations of Sakurai's object (Asplund 
et al. 1999). These stars experience a very-late thermal pulse (VLTP) where convective-reactive nucleosynthesis occurs and unprocessed, H-rich material is convectively mixed into the Heburning zone (Herwig et al. 2011). For the outer He intershell, which extends almost up to the stellar surface, Herwig et al. (2011) predict a ${ }^{12} \mathrm{C} /{ }^{13} \mathrm{C}$ ratio of $<10$ and high abundances of the first-peak $s$-process elements such as $\mathrm{Sr}, \mathrm{Y}$ and $\mathrm{Zr}$. The latter result from high neutron densities (up to a few $10^{15} \mathrm{~cm}^{-3}$ ) in the He intershell, produced by $\alpha$-capture on ${ }^{13} \mathrm{C}$ ( $i$-process; Cowan $\&$ Rose 1977). Dust around Sakurai's object is dominated by amorphous carbon (Chesneau et al. 2009). SiC dust is below the detection limit, but has been identified in spectra from post-AGB stars (Molster \& Waters 2003).

Amari et al. (2001) excluded SNe II as possible sources of AB grains. However, later work by Savina et al. (2003, 2007) revealed two AB grains whose Mo- and Ru-isotopic compositions are suggestive of a SN origin. Therefore, SNe II could be a minor source of $\mathrm{AB}$ grains. SiC grains with accepted $\mathrm{SN}$ origins (i.e., $\mathrm{X}$ and $\mathrm{C}$ grains) show characteristic $\mathrm{Si}$-isotopic anomalies, which are not seen in $\mathrm{AB}$ grains. Other isotopic fingerprints of $\mathrm{SN}$ grains, e.g., high ${ }^{26} \mathrm{Al} /{ }^{27} \mathrm{Al}(>0.1)$ and/or evidence for ${ }^{44} \mathrm{Ti}$ must thus be used to identify possible $\mathrm{AB}$ grains from $\mathrm{SNe}$ II.

In the present work, we report $\mathrm{C}-, \mathrm{N}-, \mathrm{Mg}_{-} \mathrm{Al}-, \mathrm{Si}_{-}, \mathrm{S}-$ and $\mathrm{Ca}-\mathrm{Ti}$-isotopic measurements on $34 \mathrm{AB}$ grains. These measurements were motivated by the desire to obtain further constraints on the origin of $\mathrm{AB}$ grains, in particular to investigate whether SNe II might have contributed to the population of $\mathrm{AB}$ grains and to discuss the proposed origin from born-again AGB stars.

\section{EXPERIMENTAL SET-UP}

SiC grains were extracted from a $30 \mathrm{~g}$ sample of the Murchison CM2 meteorite (Besmehn \& Hoppe 2003), by using a technique similar to that of Amari et al. (1994). Thousands of SiC grains were dispersed on several clean Au foils, one of which was used for the present study.

The search for $\mathrm{SiC} \mathrm{AB}$ grains was performed by applying the automatic grain mode analysis with the Cameca NanoSIMS 50 ion probe at Washington University (Gyngard et al. 2010b). Carbon- and $\mathrm{Si}$-isotopic measurements of $\mathrm{SiC}$ grains were carried out in three steps: First, we obtained ion images of ${ }^{12} \mathrm{C}^{-},{ }^{13} \mathrm{C}^{-},{ }^{28} \mathrm{Si}^{-},{ }^{29} \mathrm{Si}^{-}$, and ${ }^{30} \mathrm{Si}^{-}$in multi-collection mode, produced by rastering $\left(256 \times 256\right.$ pixels, $\left.5000 \mu \mathrm{s}_{\text {pixel }}^{-1}\right)$ a focused primary $\mathrm{Cs}^{+}$ion beam $(\sim 100 \mathrm{~nm}, \sim 1 \mathrm{pA})$ over $20 \times 20 \mu \mathrm{m}^{2}$ sized areas on the sample surface. Second, SiC grains were automatically identified from the ${ }^{28} \mathrm{Si}$ ion image, and then each identified SiC grain was analyzed by integrating ion intensities with integration times adjusted according to grain size. Finally, the sample stage was moved to an adjacent area and the above steps were repeated. We acquired $\mathrm{C}$ and $\mathrm{Si}$ isotope data for $\sim 2300$ presolar SiC grains from 464 areas. $105 \mathrm{AB}$ grains were identified in this way. Among those we selected 34 grains with $\mathrm{Si}$-isotopic compositions away from the Si MS line by more than $2 \sigma$ (Figure 1 ) for further analysis.

Subsequent N-, Mg-Al-, S- and Ca-Ti-isotope measurements were carried out with the NanoSIMS 50 ion probe at the Max Plank Institute for Chemistry. Sulfur-isotopic compositions were determined for all 34 grains by acquiring ${ }^{32} \mathrm{~S}^{-},{ }^{33} \mathrm{~S}^{-}$, and ${ }^{34} \mathrm{~S}^{-}$along with ${ }^{12} \mathrm{C}^{-}$and ${ }^{13} \mathrm{C}^{-}$ion images in multi-collection, produced by rastering a $\mathrm{Cs}^{+}$primary ion beam $(\sim 100 \mathrm{~nm}$, $\sim 1 \mathrm{pA})$ over $2 \times 2$ to $3 \times 3 \mu \mathrm{m}^{2}$ areas $(128 \times 128$ pixels, $15000 \mu$ s pixel $^{-1}, 1-6$ image planes) covering the AB grains.

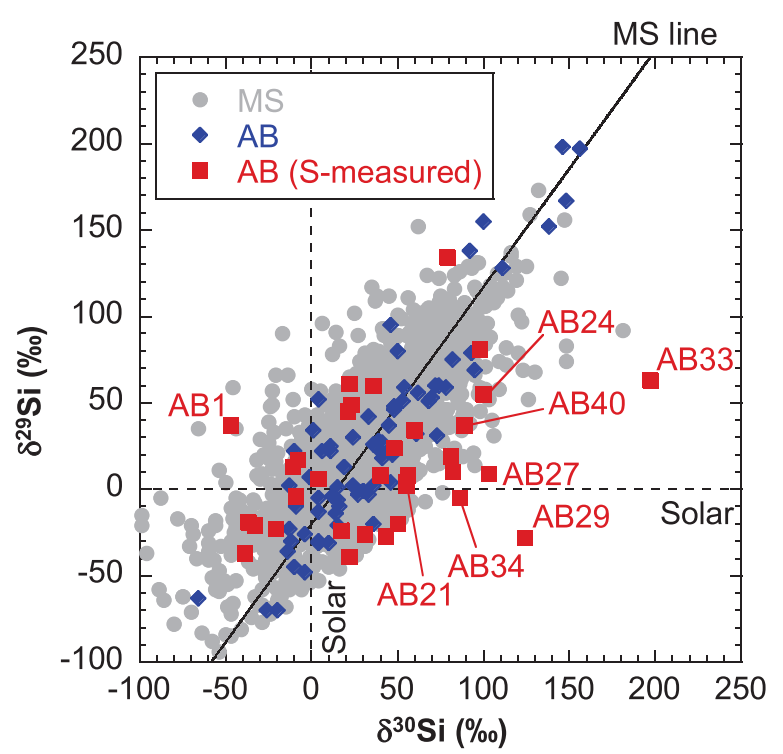

Figure 1. Silicon-isotopic compositions of presolar $\mathrm{SiC}$ AB grains identified in this work. The squares represent grains that have Si-isotopic compositions away from the MS line by more than $2 \sigma$ and which were measured for S- and in part also for $\mathrm{N}-, \mathrm{Mg}-\mathrm{Al}$-, and $\mathrm{Ca}-\mathrm{Ti}$-isotopic compositions. Other $\mathrm{AB}$ grains (diamonds) and the mainstream grains (circles) from this study are shown for reference.

(A color version of this figure is available in the online journal.)

Subsequently, we carried out $\mathrm{Al}-\mathrm{Mg}$ and $\mathrm{Ca}-\mathrm{Ti}$ isotope analyses for 20 and 10 grains, respectively. For the $\mathrm{Al}-\mathrm{Mg}$-isotope measurements, ${ }^{24} \mathrm{Mg}^{+},{ }^{25} \mathrm{Mg}^{+},{ }^{26} \mathrm{Mg}^{+},{ }^{27} \mathrm{Al}^{+}$, and ${ }^{28} \mathrm{Si}^{+}$ion images were obtained in multi-collection by rastering an $\mathrm{O}^{-}$ primary ion beam $(\sim 300-400 \mathrm{~nm}, \sim 5 \mathrm{pA})$ over $2 \times 2$ to $4 \times 4 \mu \mathrm{m}^{2}$ areas $\left(128 \times 128\right.$ pixels, $15000 \mu \mathrm{s} \mathrm{pixel}^{-1}, 4-5$ image planes). Similarly, ${ }^{28} \mathrm{Si}^{+},{ }^{40} \mathrm{Ca}^{+},{ }^{42} \mathrm{Ca}^{+},{ }^{44} \mathrm{Ca}^{+}$and ${ }^{48} \mathrm{Ti}^{+}$ ion images were acquired for the $\mathrm{Ca}-\mathrm{Ti}$ isotope measurements. Finally, $\mathrm{N}$-isotopic compositions were measured on two $\mathrm{AB}$ grains by recording ${ }^{12} \mathrm{C}^{-},{ }^{13} \mathrm{C}^{-},{ }^{26} \mathrm{CN}^{-},{ }^{27} \mathrm{CN}^{-}$, and ${ }^{28} \mathrm{Si}^{-}$ion images in a setup similar to that for the $\mathrm{S}$ isotope measurements.

\section{RESULTS AND DISCUSSION}

The isotopic compositions and trace element abundances of $34 \mathrm{AB}$ grains studied here are shown in Table 1. Their $\mathrm{Si}$ - and $\mathrm{S}$-isotopic compositions are displayed in Figures 1 and 2. The Si-isotopic compositions of the AB grains from this study are similar to those from previous studies (Amari et al. 2001). A few grains, however, show relatively large deviations from the Si MS line (AB1, AB27, AB29, AB33, AB34; see Figure 1). Typical $S$ abundances range from 0.1 to 1 weight percent; in a few cases very high $\mathrm{S}$ concentrations are observed (AB13, AB17, AB34), which indicates that AB grains are contaminated to various extent by terrestrial or meteoritic sulfur. Three grains with comparatively low $\mathrm{S}$ concentrations and no apparent $\mathrm{S}$ contamination show enrichments in ${ }^{32} \mathrm{~S}$ of $>100 \%$ at significance levels of $\geqslant 2 \sigma$ in ${ }^{33} \mathrm{~S} /{ }^{32} \mathrm{~S}$ and ${ }^{34} \mathrm{~S} /{ }^{32} \mathrm{~S}$ (AB21, AB24) or of $\sim 3 \sigma$ in ${ }^{34} \mathrm{~S} /{ }^{32} \mathrm{~S}$ (AB40; Figure 2). Eighteen out of the $20 \mathrm{AB}$ grains analyzed for $\mathrm{Mg}-\mathrm{Al}$ show excesses in ${ }^{26} \mathrm{Mg}$ with inferred ${ }^{26} \mathrm{Al} /{ }^{27} \mathrm{Al}$ ratios of typically between $10^{-3}$ and $10^{-2}$, consistent with results from previous studies (Amari et al. 2001). One grain (AB34) exhibits a ${ }^{26} \mathrm{Al} /{ }^{27} \mathrm{Al}$ ratio of $5.7 \pm 0.8 \times 10^{-2}$, the highest value for $\mathrm{AB}$ grains found so far and close to, but still lower than the typical values for $\mathrm{X}$ grains. Measurements on some grains (AB10, AB22, AB25, 
Table 1

Isotopic Compositions and Trace Element Abundances of 34 SiC AB Grains

\begin{tabular}{|c|c|c|c|c|c|c|c|c|c|c|c|}
\hline Grain & ${ }^{12} \mathrm{C} /{ }^{13} \mathrm{C}$ & ${ }^{14} \mathrm{~N} /{ }^{15} \mathrm{~N}$ & $\begin{array}{c}{ }^{26} \mathrm{Al} /{ }^{27} \mathrm{Al} \\
\left(10^{-3}\right)\end{array}$ & {$[\mathrm{Al}]^{\mathrm{a}}$} & $\begin{array}{c}\delta^{29} \mathrm{Si} \\
(\% o)\end{array}$ & $\begin{array}{c}\delta^{30} \mathrm{Si} \\
(\% o)\end{array}$ & $\begin{array}{l}\delta^{33} S \\
(\% o)\end{array}$ & $\begin{array}{l}\delta^{34} \mathrm{~S} \\
(\% o)\end{array}$ & {$[\mathrm{S}]^{\mathrm{a}}$} & $\begin{array}{c}{ }^{{ }^{44} \mathrm{Ti} /{ }^{48} \mathrm{Ti}} \\
\left(10^{-2}\right)\end{array}$ & {$[\mathrm{Ti}]^{\mathrm{a}}$} \\
\hline \multicolumn{12}{|c|}{$\mathrm{AB}$ grains with ${ }^{32} \mathrm{~S}$ excesses } \\
\hline M7_AB21 & $5.71 \pm 0.07$ & & & & $2 \pm 14$ & $55 \pm 17$ & $-600 \pm 230$ & $-340 \pm 130$ & 0.39 & $<26$ & 0.06 \\
\hline M7_AB24 & $7.44 \pm 0.06$ & & $3.28 \pm 0.96$ & 7.8 & $55 \pm 14$ & $100 \pm 17$ & $-310 \pm 140$ & $-131 \pm 67$ & 0.78 & & \\
\hline M7_AB40 & $2.33 \pm 0.01$ & & $5.3 \pm 1.2$ & 17.3 & $37 \pm 4$ & $89 \pm 4$ & $-320 \pm 200$ & $-264 \pm 90$ & 0.12 & $0.33 \pm 0.36$ & 0.15 \\
\hline \multicolumn{12}{|c|}{ Other AB grains } \\
\hline$\overline{M 7}$ MB1 & $6.05 \pm 0.02$ & $3550 \pm 570$ & $1.6 \pm 1.5$ & 9.1 & $37 \pm 6$ & $-47 \pm 7$ & $630 \pm 270$ & $34 \pm 91$ & 0.11 & $3.2 \pm 1.7$ & 0.68 \\
\hline M7_AB2 & $3.18 \pm 0.01$ & & $2.72 \pm 0.76$ & 16.7 & $45 \pm 3$ & $21 \pm 4$ & $57 \pm 82$ & $-13 \pm 34$ & 0.37 & & \\
\hline M7_AB6 & $3.89 \pm 0.02$ & & $1.91 \pm 0.42$ & 7.6 & $6 \pm 2$ & $4 \pm 3$ & $-47 \pm 116$ & $25 \pm 52$ & 1.41 & & \\
\hline M7_AB7 & $2.10 \pm 0.01$ & & & & $-37 \pm 5$ & $-39 \pm 6$ & $213 \pm 94$ & $14 \pm 37$ & 0.90 & $0.02 \pm 0.13$ & 1.59 \\
\hline M7_AB8 & $4.65 \pm 0.03$ & & $3.4 \pm 1.3$ & 2.6 & $17 \pm 7$ & $-8 \pm 8$ & $-270 \pm 170$ & $-22 \pm 84$ & 0.38 & & \\
\hline M7_AB10 & $5.27 \pm 0.09$ & & $0.19 \pm 0.11$ & 50.0 & $13 \pm 9$ & $-11 \pm 10$ & $-98 \pm 190$ & $-8 \pm 85$ & 3.06 & & \\
\hline M7_AB11 & $4.70 \pm 0.03$ & & & & $-23 \pm 5$ & $-21 \pm 7$ & $-6 \pm 140$ & $7 \pm 60$ & 1.05 & & \\
\hline M7_AB12 & $5.31 \pm 0.06$ & & $0.1 \pm 2.7$ & 12.9 & $60 \pm 7$ & $36 \pm 8$ & $-1 \pm 260$ & $-287 \pm 92$ & 0.90 & & \\
\hline M7_AB13 & $5.08 \pm 0.04$ & & & & $-21 \pm 10$ & $-33 \pm 12$ & $-68 \pm 42$ & $21 \pm 19$ & 14.2 & & \\
\hline M7_AB14 & $4.83 \pm 0.07$ & & $0.52 \pm 0.88$ & 5.3 & $-19 \pm 13$ & $-37 \pm 15$ & $89 \pm 212$ & $43 \pm 89$ & 1.86 & & \\
\hline M7_AB15 & $4.59 \pm 0.07$ & & & & $-4 \pm 7$ & $-9 \pm 8$ & $-74 \pm 226$ & $-89 \pm 95$ & 2.15 & & \\
\hline M7_AB16 & $2.93 \pm 0.03$ & & $3.80 \pm 0.74$ & 5.3 & $49 \pm 10$ & $23 \pm 12$ & $180 \pm 230$ & $-204 \pm 79$ & 0.95 & $<0.72$ & 0.85 \\
\hline M7_AB17 & $8.93 \pm 0.15$ & & & & $61 \pm 14$ & $22 \pm 17$ & $33 \pm 33$ & $-20 \pm 14$ & 73.9 & & \\
\hline M7_AB18 & $4.46 \pm 0.06$ & & $1.4 \pm 1.3$ & 4.0 & $134 \pm 14$ & $79 \pm 17$ & $78 \pm 159$ & $64 \pm 68$ & 3.26 & & \\
\hline M7_AB19 & $7.97 \pm 0.04$ & & & & $24 \pm 6$ & $48 \pm 8$ & $170 \pm 150$ & $-35 \pm 58$ & 0.42 & & \\
\hline M7_AB20 & $2.62 \pm 0.03$ & & $10.2 \pm 2.0$ & 3.9 & $-39 \pm 13$ & $22 \pm 16$ & $-400 \pm 170$ & $-62 \pm 91$ & 1.29 & $<4.0$ & 0.47 \\
\hline M7_AB22 & $8.34 \pm 0.17$ & & $<2.5$ & 27.1 & $-24 \pm 6$ & $17 \pm 8$ & $-210 \pm 230$ & $140 \pm 120$ & 1.72 & & \\
\hline M7_AB25 & $3.57 \pm 0.01$ & $63 \pm 1$ & $2.4 \pm 4.5$ & 46.2 & $34 \pm 6$ & $60 \pm 7$ & $-68 \pm 97$ & $27 \pm 44$ & 0.97 & & \\
\hline M7_AB26 & $7.52 \pm 0.02$ & & $0.55 \pm 0.80$ & 2.0 & $-27 \pm 13$ & $43 \pm 16$ & $134 \pm 59$ & $16 \pm 24$ & 0.77 & & \\
\hline M7_AB27 & $1.91 \pm 0.01$ & & $9.0 \pm 9.0$ & 7.2 & $9 \pm 19$ & $103 \pm 24$ & $110 \pm 240$ & $-228 \pm 84$ & 0.60 & $0.5 \pm 1.0$ & 0.61 \\
\hline M7_AB29 & $5.83 \pm 0.08$ & & & & $-28 \pm 27$ & $124 \pm 36$ & $470 \pm 310$ & $-35 \pm 106$ & 1.05 & & \\
\hline M7_AB30 & $7.81 \pm 0.03$ & & $<2.8$ & 6.7 & $8 \pm 4$ & $40 \pm 5$ & $-79 \pm 143$ & $152 \pm 68$ & 0.21 & $<7.5$ & 0.68 \\
\hline M7_AB31 & $8.07 \pm 0.04$ & & & & $19 \pm 9$ & $81 \pm 11$ & $-29 \pm 129$ & $90 \pm 58$ & 0.31 & & \\
\hline M7_AB33 & $6.55 \pm 0.05$ & & & & $63 \pm 17$ & $197 \pm 22$ & $-89 \pm 115$ & $44 \pm 53$ & 1.14 & & \\
\hline M7_AB34 & $5.49 \pm 0.10$ & & $56.5 \pm 8.2$ & 12.2 & $-5 \pm 10$ & $86 \pm 12$ & $110 \pm 120$ & $-57 \pm 49$ & 8.78 & & \\
\hline M7_AB35 & $4.24 \pm 0.02$ & & & & $81 \pm 3$ & $98 \pm 4$ & $200 \pm 150$ & $82 \pm 65$ & 0.28 & $0.39 \pm 0.31$ & 0.13 \\
\hline M7_AB36 & $2.85 \pm 0.01$ & & $13.5 \pm 1.6$ & 35.4 & $-20 \pm 5$ & $50 \pm 7$ & $-340 \pm 150$ & $-4 \pm 79$ & 0.14 & $<0.20$ & 1.64 \\
\hline M7_AB37 & $2.19 \pm 0.01$ & & & & $4 \pm 4$ & $55 \pm 5$ & $56 \pm 69$ & $-87 \pm 27$ & 1.57 & $1.2 \pm 0.7$ & 0.31 \\
\hline M7_AB38 & $1.85 \pm 0.00$ & & $2.08 \pm 0.62$ & 14.8 & $8 \pm 4$ & $56 \pm 5$ & $116 \pm 74$ & $-11 \pm 30$ & 0.34 & & \\
\hline M7_AB39 & $6.03 \pm 0.02$ & & & & $10 \pm 5$ & $82 \pm 7$ & $1 \pm 130$ & $80 \pm 57$ & 0.24 & & \\
\hline M7_AB41 & $9.90 \pm 0.06$ & & & & $-26 \pm 3$ & $31 \pm 3$ & $120 \pm 100$ & $14 \pm 42$ & 0.90 & & \\
\hline Average $^{\mathrm{b}}$ AB21, 24, 40 & $3.09 \pm 0.01$ & & $4.65 \pm 0.86$ & & $36 \pm 3$ & $88 \pm 4$ & $-360 \pm 100$ & $-202 \pm 49$ & 0.43 & $0.24 \pm 0.42$ & \\
\hline SN model A & 17 & & 3.97 & & 30 & 90 & -253 & -234 & & 0.06 & \\
\hline SN model B & $2.2 \times 10^{5}$ & & 4.1 & & 33 & 91 & -250 & -250 & & 4.65 & \\
\hline Born-again AGB model & 8.2 & 790 & 0.0044 & & 37 & 161 & & & & & \\
\hline
\end{tabular}

Notes.

a Weight percent.

b Averages are calculated by adding counts from individual measurements. Errors are $1 \sigma$ and are based on counting statistics only.

AB36) gave very high $\mathrm{Al}$ abundances, which must be caused by $\mathrm{Al}$ contamination. No grains show significant ${ }^{42} \mathrm{Ca} /{ }^{40} \mathrm{Ca}$ and ${ }^{44} \mathrm{Ca} /{ }^{40} \mathrm{Ca}$ anomalies of $>2 \sigma$, and therefore there is no clear evidence for extinct ${ }^{44} \mathrm{Ti}$.

In the following, we concentrate on the three grains with significant ${ }^{32} \mathrm{~S}$ excesses. On average, these three grains have $\delta^{33} \mathrm{~S} \sim-360 \%$ and $\delta^{34} \mathrm{~S} \sim-200 \%$ o. Given the relatively small number of analyzed grains, it is unlikely that the ${ }^{32} \mathrm{~S}$ excesses of these three grains just represent statistical outliers. Neither AGB stars nor novae are expected to produce lower than solar ${ }^{33} \mathrm{~S} /{ }^{32} \mathrm{~S}$ (and ${ }^{34} \mathrm{~S} /{ }^{32} \mathrm{~S}$ for AGB stars) ratios (José et al. 2004; Cristallo et al. 2009). Galactic chemical evolution (GCE) may account for moderate variations of S-isotopic compositions (Kobayashi et al. 2011). But it should be noted that no MS grains show large ${ }^{32} \mathrm{~S}$ excesses as inferred from a study of a few large MS grains (LU and LS separates; Gyngard et al. 2007).
The Rauscher et al. (2002) SN II models predict large enrichments in ${ }^{32} \mathrm{~S}$ for the $\mathrm{Si} / \mathrm{S}$ zone, dominated by ${ }^{28} \mathrm{Si}$ and ${ }^{32} \mathrm{~S}$ (Figure 3). Simple ad hoc SN mixing models predict ${ }^{32} \mathrm{~S}$ excesses to be accompanied by ${ }^{28} \mathrm{Si}$ excesses, which are not observed here. If we assume that the ${ }^{32} \mathrm{~S}$ excesses originate from the $\mathrm{Si} / \mathrm{S}$ zone, we must invoke $\mathrm{S}-\mathrm{Si}$ fractionation due to sulfur molecule chemistry in the still unmixed SN II ejecta (Hoppe et al. 2012) to explain the $\mathrm{Si}$ - and $\mathrm{S}$-isotopic signatures of the three $\mathrm{AB}$ grains. If we consider selective mixing of matter from different zones in the $15 M_{\odot}$ SN II model of Rauscher et al. (2002) in proportions $\mathrm{Si} / \mathrm{S}: \mathrm{O} / \mathrm{Si}: \mathrm{He} / \mathrm{N}: \mathrm{H}=$ 0.0028:0.0094:0.25:1 (mass fractions of whole zones), and assume preferential trapping of $\mathrm{S}$ from the $\mathrm{Si} / \mathrm{S}$ zone by a factor of 20, we find a fairly good match between the observed and predicted isotopic compositions (model A, Table 1). The only mismatch between the grain data and the model prediction exists 


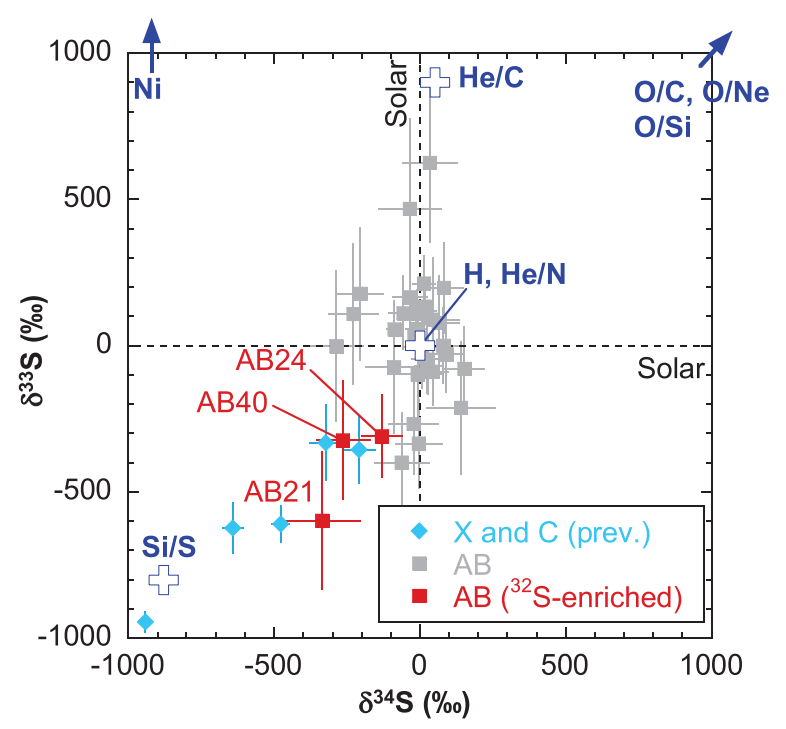

Figure 2. Sulfur-isotopic compositions of $34 \mathrm{SiC}$ AB grains. Three grains (AB21, 24 and 40) show large ${ }^{32} \mathrm{~S}$ excesses of $>100 \%$. Also shown are $\mathrm{X}$ and $\mathrm{C}$ grains with significant $\mathrm{S}$ isotope anomalies from previous studies (Gyngard et al. 2010a; Hoppe et al. 2012; Xu et al. 2012). The predicted S-isotopic compositions of the different zones in a $15 M_{\odot}$ SN II (Rauscher et al. 2002) are shown by crosses and arrows for comparison.

(A color version of this figure is available in the online journal.)

for the $\mathrm{C}$-isotopic composition; the average ${ }^{12} \mathrm{C} /{ }^{13} \mathrm{C}$ ratio of the three grains is $\sim 3$ while the predicted value is 17 . In SN II models, very low ${ }^{12} \mathrm{C} /{ }^{13} \mathrm{C}$ ratios of $\sim 3$ are predicted for the $\mathrm{He} / \mathrm{N}$ zone, but contributions of matter from this zone must be limited because of the observed low ${ }^{26} \mathrm{Al}$ abundances (the $\mathrm{He} / \mathrm{N}$ zone is a major production site for ${ }^{26} \mathrm{Al}$; Figure 3 ).

Recently, Pignatari et al. (2013b) presented an alternative explanation for ${ }^{32} \mathrm{~S}$ excesses in $\mathrm{C}$ grains: decay of radioactive ${ }^{32} \mathrm{Si}$, produced by $\mathrm{n}$-capture reactions in the $\mathrm{C}$-rich explosive $\mathrm{He} / \mathrm{C}$ zone. This scenario is attractive because the ad hoc assumption of $\mathrm{Si}-\mathrm{S}$ fractionation due to $\mathrm{S}$ molecule chemistry in SN ejecta can be avoided and because the very large ${ }^{32} \mathrm{~S}$ excess found by $\mathrm{Xu}$ et al. (2012) in a $\mathrm{C}$ grain, larger than what is predicted for $\mathrm{S}$ in the $\mathrm{Si} / \mathrm{S}$ zone (Figure 2), can easily be explained. If we follow the approach of Pignatari et al. (2013b), assuming that all ${ }^{33} \mathrm{~S}$ and ${ }^{34} \mathrm{~S}$ in the three $\mathrm{AB}$ grains is contamination, ${ }^{32} \mathrm{Si} /{ }^{28} \mathrm{Si}$ is calculated from $-0.001 \times \delta \mathrm{S} \times$ ${ }^{32} \mathrm{~S} /{ }^{28} \mathrm{Si}$, where $\delta \mathrm{S}$ is the average of $\delta^{33} \mathrm{~S}$ and $\delta^{34} \mathrm{~S}$. With $\delta \mathrm{S}=-250 \%$ (weighted average of our three $\mathrm{AB}$ grains) and ${ }^{32} \mathrm{~S} /{ }^{28} \mathrm{Si}=5 \times 10^{-3}$ we obtain ${ }^{32} \mathrm{Si} /{ }^{28} \mathrm{Si}=1.3 \times 10^{-3}$. The model of Pignatari et al. (2013b) predicts ${ }^{32} \mathrm{Si} /{ }^{28} \mathrm{Si}$ ratios on the order of $10^{-4}$ to $10^{-3}$, similar to those inferred for SN grains, in certain regions of the $\mathrm{C}$-rich explosive He shell. From the $15 M_{\odot}$ SN II model of Rauscher et al. (2002), in which ${ }^{32} \mathrm{Si}$ is significantly produced in the outer part of the $\mathrm{O} / \mathrm{C}$ zone (Figure 3), the average Si-isotopic compositions, and ${ }^{26} \mathrm{Al} /{ }^{27} \mathrm{Al}$ and ${ }^{32} \mathrm{Si} /{ }^{28} \mathrm{Si}$ ratios can be well reproduced if matter from the $\mathrm{Si} / \mathrm{S}, \mathrm{O} / \mathrm{Ne}$, and $\mathrm{O} / \mathrm{C}$ (only outer $0.2 M_{\odot}$ ) zones are mixed in proportions 0.0163:0.0136:1 (SN model B, Table 1). However, the ${ }^{32} \mathrm{Si}$-rich material from the $\mathrm{C}$-rich layer of Pignatari et al. (2013b) and the mixture in SN model $\mathrm{B}$ have high ${ }^{12} \mathrm{C} /{ }^{13} \mathrm{C}$ ratios typical of He burning conditions, which is not compatible with the $\mathrm{AB}$ grain signatures. Admixture of matter from the ${ }^{13} \mathrm{C}$-rich $\mathrm{He} / \mathrm{N}$ zone is not able to resolve this problem because it would make ${ }^{26} \mathrm{Al} /{ }^{27} \mathrm{Al}$ significantly higher than observed. Therefore, in view of no evidence for ${ }^{44} \mathrm{Ti}$, the relatively low ${ }^{26} \mathrm{Al} /{ }^{27} \mathrm{Al}$ ratios, and especially the low ${ }^{12} \mathrm{C} /{ }^{13} \mathrm{C}$ ratios of the

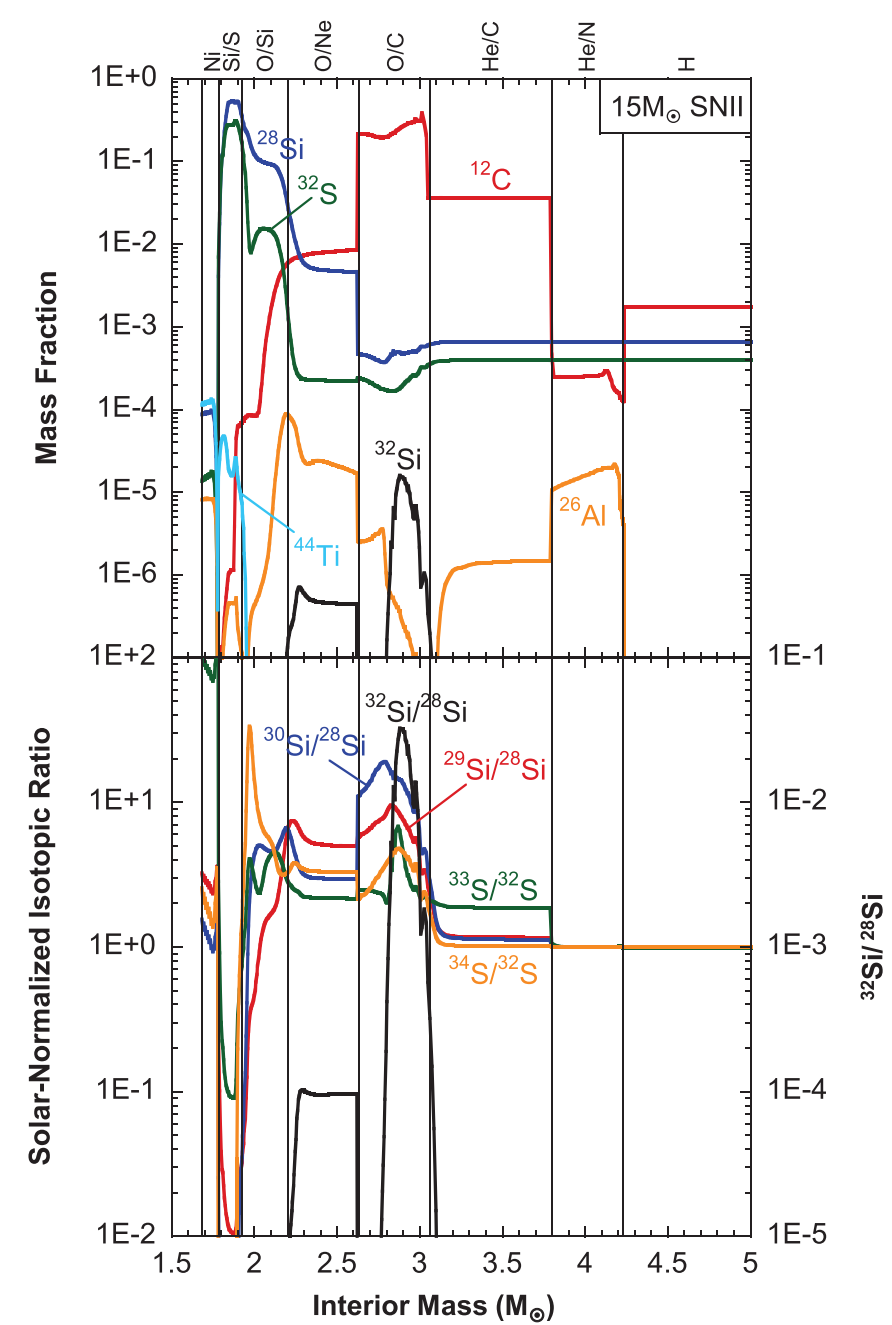

Figure 3. Mass fractions of ${ }^{12} \mathrm{C},{ }^{26} \mathrm{Al},{ }^{28} \mathrm{Si},{ }^{32} \mathrm{Si},{ }^{32} \mathrm{~S}$ and ${ }^{44} \mathrm{Ti}$ (upper panel), and solar-normalized ratios of ${ }^{29,30} \mathrm{Si} /{ }^{28} \mathrm{Si}$ and ${ }^{33,34} \mathrm{~S} /{ }^{32} \mathrm{~S}$ (lower panel, left scale), and the ${ }^{32} \mathrm{Si} /{ }^{28} \mathrm{Si}$ ratio (lower panel, right scale) in the interior of a $15 M_{\odot} \mathrm{SN}$ II model (Rauscher et al. 2002). The different SN zones are shown at the top of this figure.

(A color version of this figure is available in the online journal.)

grains, a possible $\mathrm{SN}$ origin of our three $\mathrm{AB}$ grains with ${ }^{32} \mathrm{~S}$ excesses seems unlikely for both stellar models considered, although it cannot be completely excluded due to the large uncertainties affecting those models and present limitations in our understanding of core-collapse SN explosions in general. Note that mixtures in both $\mathrm{SN}$ models have $\mathrm{C} / \mathrm{O}<1$. It is not favorable for the formation of carbonaceous dust, although Clayton et al. (1999) argued that carbon dust can condense even when $\mathrm{C} / \mathrm{O}<1$.

We will thus reconsider born-again AGB stars and investigate whether such stars can produce ${ }^{32} \mathrm{~S}$ excesses. First, we explored the $i$-process in a one-zone $\mathrm{He}$ intershell with initially high abundances of protons and ${ }^{12} \mathrm{C}$, such as they occur in the VLTP in post-AGB star Sakurai's object (Asplund et al. 1999; Werner \& Herwig 2006; Herwig et al. 2011). The key ingredient of the $i$-process is strong proton capture resulting in an efficient production of neutrons due to the ${ }^{13} \mathrm{C}(\alpha, \mathrm{n}){ }^{16} \mathrm{O}$ activation. A onezone He intershell, burning at a constant temperature of $2 \times 10^{8}$ $\mathrm{K}$ and $\rho=10^{4} \mathrm{~g} / \mathrm{cm}^{3}$, and an initial abundance of $\mathrm{X}\left({ }^{1} \mathrm{H}\right)=0.2$, $\mathrm{X}\left({ }^{12} \mathrm{C}\right)=0.5$, and $\mathrm{X}\left({ }^{16} \mathrm{O}\right)=0.35$, with all other species having solar abundances (Asplund 2005), produces a neutron density of $N_{n} \sim 10^{15} \mathrm{~cm}^{-3}$, which defines the $i$-process. This neutron 


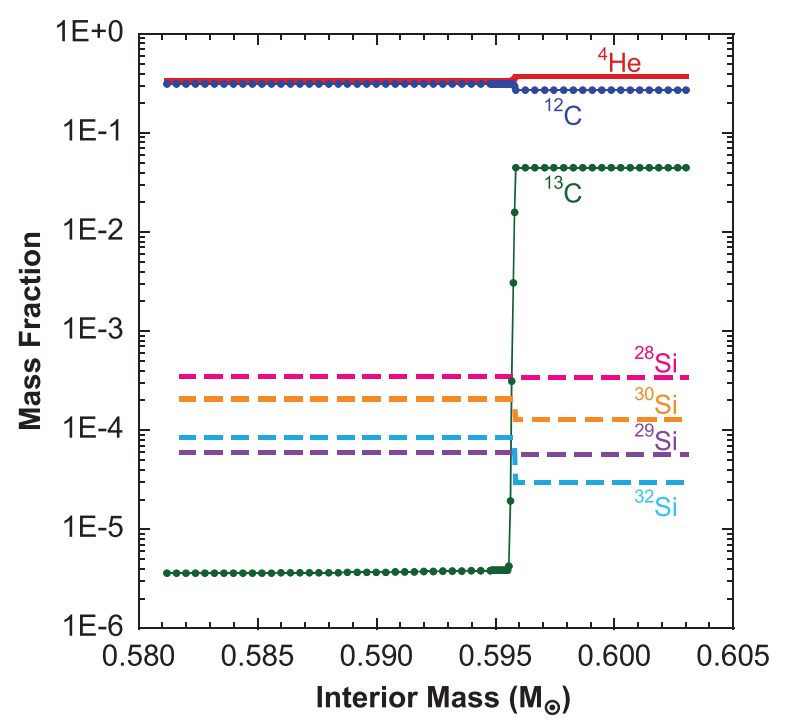

Figure 4. Mass fractions of ${ }^{4} \mathrm{He}$, and $\mathrm{C}$ and $\mathrm{Si}$ isotopes in the He intershell of a born-again AGB star predicted by the model (RUN106) of Herwig et al. (2011). (A color version of this figure is available in the online journal.)

density is much higher than the highest $s$-process values of $N_{n} \sim 10^{11-12} \mathrm{~cm}^{-3}$, but much lower than in $r$-process conditions with $N_{n}>10^{20} \mathrm{~cm}^{-3}$. Significant amounts of radioactive ${ }^{32} \mathrm{Si}$ are predicted to be produced after $1.1 \mathrm{hr}$, reaching a maximum when large amounts of the first-peak $s$-process elements (e.g., $\mathrm{Sr}, \mathrm{Y}$ and $\mathrm{Zr}$ ) are produced, but before significant production of the second-peak $s$-process elements (e.g., Ba and La). This matches well the elemental abundances observed in Sakurai's object, which seems not to have experienced any relevant $s$-process during its AGB phase. Variations in $s$-process element abundances of AB grains found by Amari et al. (2001) could reflect the fact that $\mathrm{AB}$ grains condensed also around post-AGB stars which experienced significant $s$-processing, producing the second-peak $s$-process elements before the $i$-process activation.

Second, we used the one-dimensional, multi-zone model of Herwig et al. (2011) to calculate abundance profiles of $\mathrm{C}$ and $\mathrm{Si}$ isotopes in the $\mathrm{He}$ intershell (Figure 4). Model RUN106 of Herwig et al. (2011) produces an abundance ratio of the second- to first-peak $s$-process elements close to that observed in Sakurai's object (Asplund et al. 1999). In the outer He intershell, a ${ }^{32} \mathrm{Si} /{ }^{28} \mathrm{Si}$ ratio of $\sim 8 \times 10^{-2}$ is predicted, significantly higher than that inferred for our $\mathrm{AB}$ grains. If we assume mixing with unprocessed material of solar composition in a ratio $1: 35$ by mass (this corresponds to a ${ }^{28} \mathrm{Si}$ abundance ratio of 1:60), it is possible to reproduce the inferred ${ }^{32} \mathrm{Si} /{ }^{28} \mathrm{Si}$ ratio of $\sim 10^{-3}$ in $A B$ grains. The dilution factor of 35 may be achieved if a likely gradient of $i$-process products in the outermost zones is considered, as it was observed on the surface of Sakurai's object over a timescale of a few months. However, a proper treatment requires full multi-dimensional hydrodynamic simulations including the energy feedback during $\mathrm{H}$ ingestion (Herwig et al. 2011 and references therein), which is beyond the scope of this Letter. Along with ${ }^{32} \mathrm{Si}$, significant amounts of ${ }^{29} \mathrm{Si}$ and ${ }^{30} \mathrm{Si}$ are produced, with higher enrichments in ${ }^{30} \mathrm{Si}$ than ${ }^{29} \mathrm{Si}$. With the assumed dilution of a factor of 35 with isotopically normal material, and ${ }^{29} \mathrm{Si} /{ }^{28} \mathrm{Si}=0.16$ and ${ }^{30} \mathrm{Si} /{ }^{28} \mathrm{Si}=0.35$ resulting from the $i$-process (Figure 4), we obtain $\delta^{29} \mathrm{Si}=37 \%$ o and $\delta^{30} \mathrm{Si}=161 \%$. Considering the limitations of the VLTP model used here and the fact that it is based only on one mass and one metallicity, we find the difference between predicted and observed $\delta^{30} \mathrm{Si}$ acceptable (Table 1). Models of born-againAGB stars predict ${ }^{12} \mathrm{C} /{ }^{13} \mathrm{C}$ ratios of $<10$ in the outer region of the $\mathrm{He}$ intershell along with high $\mathrm{C}$ abundances of more than 100 times the solar value. In a 1:35 mixture of $\mathrm{He}$ intershell material and material of solar composition, $\mathrm{C}$ is dominated by $\mathrm{C}$ from the $\mathrm{He}$ intershell and the ${ }^{12} \mathrm{C} /{ }^{13} \mathrm{C}$ ratio of the mixture will be relatively close to that in the outer $\mathrm{He}$ intershell. In RUN106, ${ }^{12} \mathrm{C} /{ }^{13} \mathrm{C}=6.6$ is predicted for the He intershell, which gives ${ }^{12} \mathrm{C} /{ }^{13} \mathrm{C}=8.2$ in the mixture. The predicted ${ }^{26} \mathrm{Al} /{ }^{27} \mathrm{Al}$ is $4.4 \times 10^{-6}$, much lower than observed in the grains. $\mathrm{A}$ higher ${ }^{26} \mathrm{Al} /{ }^{27} \mathrm{Al}$ and slightly lower ${ }^{12} \mathrm{C} /{ }^{13} \mathrm{C}$ could be achieved if the parent stars experienced cool bottom processing during their AGB phase (Nollett et al. 2003). ${ }^{14} \mathrm{~N} /{ }^{15} \mathrm{~N}$ is predicted to be 790 .

In conclusion, born-again AGB stars appear to be stellar sites that provide a natural source of ${ }^{32} \mathrm{~S}$ excesses via radioactive ${ }^{32} \mathrm{Si}$ decay along with low ${ }^{12} \mathrm{C} /{ }^{13} \mathrm{C}$ ratios, as observed in some $\mathrm{AB}$ grains. The models of Herwig et al. (2011) used here are one dimensional and spherically symmetric and it will be interesting to see whether full three-dimensional models can quantitatively match the grain data in a self-consistent way. Also, future investigations are needed to evaluate the effect of GCE and heterogeneities in the ISM on S-isotopic compositions.

We thank Joachim Huth for the SEM analyses, Elmar Gröner for technical support on the NanoSIMS, and Alexander Heger for providing detailed SN data on www.nucleosynthesis.org. W.F. acknowledges support by Grant-in-Aid for Research Fellows of the Japan Society for the Promotion of Science (JSPS). E.Z. was supported by NASA grant NNX11AH14G. NuGrid acknowledges support from NSF grants PHY 02-16783 and PHY 09-22648 (Joint Institute for Nuclear Astrophysics, JINA) and EU MIRG-CT-2006-046520. The continued work on codes and dissemination of data is made possible through funding from STFC and NWERS Discovery grant (F.H., Canada), and an Ambizione grant of the SNSF (M.P., Switzerland). M.P. also thank for support from EuroGENESIS. NuGrid data is served by Canfar/CADC. We thank an anonymous reviewer for helpful and constructive comments.

\section{REFERENCES}

Amari, S., Lewis, R. S., \& Anders, E. 1994, GeCoA, 58, 459

Amari, S., Nittler, L. R., Zinner, E., Lodders, K., \& Lewis, R. S. 2001, ApJ, 559,463

Asplund, M. 2005, ARA\&A, 43, 481

Asplund, M., Lambert, D. L., Kipper, T., Pollacco, D., \& Shetrone, M. D. 1999, A\&A, 343, 507

Besmehn, A., \& Hoppe, P. 2003, GeCoA, 67, 4693

Chesneau, O., Clayton, G. C., Lykou, F., et al. 2009, A\&A, 493, L17

Clayton, D. D., Liu, W., \& Dalgarno, A. 1999, Sci, 283, 1290

Cowan, J. J., \& Rose, W. K. 1977, ApJ, 202, 149

Cristallo, S., Straniero, O., Gallino, R., et al. 2009, ApJ, 696, 797

Gyngard, F., Amari, S., Zinner, E., Gallino, R., \& Lewis, R. S. 2007, in 38th Lunar Planet. Sci. Conf., abstract 1963

Gyngard, F., Nittler, L. R., \& Zinner, E. 2010a, M\&PS, 45, A72

Gyngard, F., Zinner, E., Nittler, L. R., et al. 2010b, ApJ, 717, 107

Hedrosa, R. P., Abia, C., Busso, M., et al. 2013, ApJL, 768, L11

Herwig, F., Pignatari, M., Woodward, P. R., et al. 2011, ApJ, 727, 89

Hoppe, P., Fujiya, W., \& Zinner, E. 2012, ApJL, 745, L26

Hoppe, P., Strebel, R., Eberhardt, P., Amari, S., \& Lewis, R. S. 1996, Sci, 272,1314

Hoppe, P., Strebel, R., Eberhardt, P., Amari, S., \& Lewis, R. S. 2000, M\&PS, 35,1157

José, J., Hernanz, M., Amari, S., Lodders, K., \& Zinner, E. 2004, ApJ, 612,414 
Kobayashi, C., Karakas, A. I., \& Umeda, H. 2011, MNRAS, 414, 3231

Lambert, D. L., Gustafsson, B., Eriksson, K., \& Hinkle, K. H. 1986, ApJS, 62,373

Lin, Y., Gyngard, F., \& Zinner, E. 2010, ApJ, 709, 1157

Lugaro, M., Davis, A. M., Gallino, R., et al. 2003, ApJ, 593, 486

Molster, F. J., \& Waters, L. B. F. M. 2003, in Astromineralogy, ed. T. Henning (New York: Springer), 121

Nittler, L. R., Amari, S., Zinner, E., Woosley, S. E., \& Lewis, R. S. 1996, ApJL, 462, L31

Nollett, K. M., Busso, M., \& Wasserburg, G. J. 2003, ApJ, 582, 1036

Pignatari, M., Wiescher, M., Timmes, F. X., et al. 2013a, ApJL, 767, L22

Pignatari, M., Zinner, E., Bertolli, M. G., et al. 2013b, ApJL, 771, L7

Rauscher, T., Heger, A., Hoffman, R. D., \& Woosley, S. E. 2002, ApJ, 576,323
Savina, M. R., Pellin, M. J., Davis, A. M., Lewis, R. S., \& Amari, S. 2007, in 38th Lunar Planet. Sci. Conf., abstract 2231

Savina, M. R., Tripa, C. E., Pellin, M. J., et al. 2003, in 34th Lunar Planet. Sci. Conf., abstract 2079

Timmes, F. X., Woosley, S. E., Hartmann, D. H., \& Hoffman, R. D. 1996, ApJ, 464, 332

Werner, K., \& Herwig, F. 2006, PASP, 118, 183

Woosley, S. E., Arnett, W. D., \& Clayton, D. D. 1973, ApJS, 26, 231

Xu, Y. C., Amari, S., Gyngard, F., Zinner, E., \& Lin, Y. 2012, M\&PS, 47, abstract 5104

Zhang, X., \& Jeffery, S. 2012, MNRAS, 426, L81

Zinner, E. 2007, in Meteorites, Comets, and Planets, ed. A. M. Davis (Amsterdam: Elsevier), 1

Zinner, E., Nittler, L. R., Gallino, R., et al. 2006, ApJ, 650, 350 